\title{
Osteoselection supported by phase separated polymer blend films
}

\author{
Hilal Unal Gulsuner, ${ }^{1}$ Nevin Atalay Gengec, ${ }^{2}$ Murat Kilinc, ${ }^{1}$ H. Yildirim Erbil, ${ }^{2}$ Ayse B. Tekinay ${ }^{1}$ \\ ${ }^{1}$ Institute of Materials Science and Nanotechnology, National Nanotechnology Research Center (UNAM), Bilkent University, \\ Ankara 06800, Turkey \\ ${ }^{2}$ Department of Chemical Engineering, Faculty of Engineering, Gebze Institute of Technology, Gebze 41400, Kocaeli, Turkey
}

Received 9 September 2013; revised 7 March 2014; accepted 7 March 2014

Published online 21 March 2014 in Wiley Online Library (wileyonlinelibrary.com). DOI: 10.1002/jbm.a.35164

\begin{abstract}
The instability of implants after placement inside the body is one of the main obstacles to clinically succeed in periodontal and orthopedic applications. Adherence of fibroblasts instead of osteoblasts to implant surfaces usually results in formation of scar tissue and loss of the implant. Thus, selective bioadhesivity of osteoblasts is a desired characteristic for implant materials. In this study, we developed osteoselective and biofriendly polymeric thin films fabricated with a simple phase separation method using either homopolymers or various blends of homopolymers and copolymers. As adhesive and proliferative features of cells are highly dependent on the physicochemical properties of the surfaces, substrates with distinct chemical heterogeneity, wettability, and surface topography were developed and assessed for their osteoselective characteristics. Surface characterizations of the fabricated polymer thin films were performed with optical microscopy and SEM, their wettabilities were determined by contact angle meas-
\end{abstract}

urements, and their surface roughness was measured by profilometry. Long-term adhesion behaviors of cells to polymer thin films were determined by F-actin staining of Saos2 osteoblasts, and human gingival fibroblasts, HGFs, and their morphologies were observed by SEM imaging. The biocompatibility of the surfaces was also examined through cell viability assay. Our results showed that heterogeneous polypropylene polyethylene/polystyrene surfaces can govern Saos-2 and HGF attachment and organization. Selective adhesion of Saos-2 osteoblasts and inhibited adhesion of HGF cells were achieved on micro-structured and hydrophobic surfaces. This work paves the way for better control of cellular behaviors for adjustment of cell material interactions. (c) 2014 Wiley Periodicals, Inc. J Biomed Mater Res Part A: 103A: 154-161, 2015.

Key Words: phase separation, polymer thin film, micro-structure, Saos-2, human gingival fibroblast, osteoselection

How to cite this article: Gulsuner HU, Gengec NA, Kilinc M, Erbil HY, Tekinay AB. 2015. Osteoselection supported by phase separated polymer blend films. J Biomed Mater Res Part A 2015:103A:154-161.

\section{INTRODUCTION}

Use of metal implants to replace hard tissues has been an important means of treatment for many types of hard tissue injuries and degeneration in periodontology and orthopedics. Biocompatibility of implants after placement inside the body is a prerequisite for these treatments. Material implantation is followed by inflammatory response in the body, which results in encapsulation of the material surface with fibrous tissue. Fibrous tissue limits the success of osseointegration of the implants. ${ }^{1}$ Thus, rapid bone ingrowth around the implant site is very important to enhance osseointegration and thereby stability and lifetime of the implant. ${ }^{2}$ Materials that aim to improve the osseointegration capability of the implants should have enhanced affinity to bone cells and decreased affinity to fibroblasts. Adherence of osteoblast or fibroblast cells onto an implant surface is mediated with an adsorbed protein layer on top of the surface which serves as ligands for cell receptors. ${ }^{3}$ The amount and conformation of adsorbed proteins (e.g., fibronectin, collagen, and laminin) on the surface in turn alter adhesion, spreading, proliferation, and differentiation behaviors of cells.

Cell adhesion on implants is a complex process since physicochemical properties of surfaces influence the nature of binding. Response of cells to the surface varies according to materials' chemical composition, surface wettability, surface energy, surface charge, and topography. ${ }^{4}$ Recent studies demonstrate that hydrophobic materials show higher protein adsorption when compared to hydrophilic surfaces; therefore, cellular activity is enhanced on these surfaces. ${ }^{5-8}$ There are also studies demonstrating the importance of hydrophilicity for enhanced cell activity and growth. ${ }^{9-11}$ Variations among these studies indicate the contribution of other factors affecting cell adhesion and function. Influence of surface topography on adhesion of osteoblast cells is known to be very important. Micro and nano structures alter cellular behaviors; and therefore, can improve fixation of implant and rate of osseointegration. ${ }^{12,13}$ Micro-scale surface roughness also regulates cell adhesion by affecting 
disposition of various integrin subunits. ${ }^{14}$ In addition, surface chemistry affects the amount of protein binding on the surface and its presentation, leading to changes in focal adhesion assemblies. ${ }^{15}$ By changing these properties one can control protein adsorption and conformation to regulate the biological activity of adhered cells. There are various techniques to control surface morphology and chemical heterogeneity like inkjet printing, ${ }^{16}$ soft lithography, ${ }^{17}$ photolithography, ${ }^{18}$ ultraviolet (UV) irradiation, ${ }^{19}$ and laser-guided cell-writing. ${ }^{20}$ However, these techniques require expensive coatings and chemicals, and complex methodologies. Moreover, their scaling up for coating of larger areas of implants is not convenient.

Polymer thin films have been widely used for biomedical applications because of their great versatility in chemical groups and their ease in processing. ${ }^{21,22}$ Polymeric surfaces with micro- and nano-rough morphologies can be obtained by a simple phase separation method using cheap commercial polymers. ${ }^{23}$

In this study, various micro-structured polymer surfaces with distinct wettability and chemical heterogeneity were fabricated by a simple phase separation process using solvent/non-solvent mixtures. Thin films on the surfaces were prepared by either homopolymers or blends of homopolymers and copolymers. Substrates having different sized micropatterns were obtained by mixing polymer blends in various concentration ratios with a non solvent. Immiscibility of the mixed polymers determined the morphology of the thin films. Dip-coated polymer blends on coverglass slides led to formation of either pits or islands on the surfaces with varying diameters. Then a combined systematic screen was applied to Saos-2 human osteoblast-like cells and human gingival fibroblasts (HGFs) to investigate their shortand long-term adhesion profiles on these surfaces to finally prescribe an optimal interface of osteoselective ability. The rapid adhesion and spreading of cells on the surface involves van der Waals interactions, ionic forces, hydrogen bonding, and electrostatic interactions. Conversely, long-term adhesion requires cell-cell interactions and cell-surface interactions which are governed by extracellular matrix proteins, cell membrane proteins, and cytoskeletal proteins that regulate cell signaling. Cell signaling in turn affects cell spreading and proliferation. As a result of our analysis, the combination of polypropylene polyethylene (PPPE) copolymer and polystyrene (PS) homopolymer with the addition of non-solvent EtOH was found to enhance adhesion of osteoblast-like cells and decrease adhesion of fibroblasts. Other surfaces showed a still selective but opposite profile where fibroblast adhesion was enhanced and osteoblast adhesion was decreased. These results indicate that cell selective surfaces that can be used for implant coatings can be produced with this economical and easy to scale-up method.

\section{MATERIALS AND METHODS Materials}

Polyvinyl alcohol (PVOH, Merck, MW = 160,000), polystyrene (PS, Sigma Aldrich, MW =350,000), high-density polyethylene (HDPE, Basell, HOSTALEN-GM8255, MW >1,000,000), and polypropylene-polyethylene copolymer elastomer containing $12 \%$ polyethylene content by weight (PPPE, Dow Chemical, VERSIFY 2300) were purchased and used as received. These polymers were dissolved in tetrahydrofuran (THF) (Merck), xylene, and toluene solvents (Tekkim, Turkey) to prepare polymer solutions. Ethanol (Merck) was used as non-solvent. Ultrapure water, diodomethane $\left(\mathrm{MeI}_{2}\right)$, formamide, $\alpha$-bromonaphthalene, and ethylene glycol (all from Merck) were used as contact angle drop liquids. Round glass coverslips (Thermo Scientific) with diameters of 13 and 15 $\mathrm{mm}$ were used as substrates to be coated by the polymer films after cleaning with chromic acid solutions. Ultrapure water was used for the final cleaning of the glass slides. Twenty-four-well plates were obtained from BD. All other materials used in this study were analytical grade and purchased from Invitrogen and Sigma-Aldrich.

\section{Preparation of homopolymer and copolymer films}

PVOH was dissolved in water, PS in toluene, HDPE in xylene, and PPPE in THF solvents at a concentration of $10 \mathrm{mg} / \mathrm{mL}$. Non-solvent ethanol (EtOH) was added to PS and PPPE polymer solutions which were prepared in THF solvent at various ratios $(4 \%, 10 \%, 14 \%$, and $18 \% \mathrm{v} / \mathrm{v})$. Round glass coverslips were coated by dip coating in these polymer solutions. The withdrawal rate of the mechanical dipper was varied between 320 and $764 \mathrm{~mm} / \mathrm{min}$. Round glass coverslips were kept in the polymer solution for $1 \mathrm{~min}$ to reach thermal equilibrium, and then withdrawn at a constant speed. Dip coating was applied at room temperature for $\mathrm{PVOH}$ and PS polymers; at $60^{\circ} \mathrm{C}$ for PPPE; and at $115^{\circ} \mathrm{C}$ for HDPE. Surface roughness and the shape and size of the formed patterns on the samples varied due to phase separation of polymer chains during sample removal, depending on the rate of solvent evaporation. Surface sulfonation was performed by submerging the PS samples in a solution of sulfuric acid (60 vol \%) for $24 \mathrm{~h}$. Sulfonated PS surfaces (PS-S) were rinsed in deionized water, and air-dried.

Coated polymer films were kept in a desiccator for 3-4 $\mathrm{h}$ and completely dried in a vacuum oven at $40^{\circ} \mathrm{C}$ overnight. The thicknesses of the coatings were calculated from the weight increase on the glass slides before and after dip coating using the density of the polymer and total coated area. The thicknesses of the coatings varied between 0.5 and $2.0 \mu \mathrm{m}$.

\section{Preparation of PS/PPPE and PS/HDPE blend films}

PS and HDPE polymer stock solutions were prepared in xylene solvent; and PS and PPPE polymers were in THF at a constant concentration of $10 \mathrm{mg} / \mathrm{mL}$. These polymers were dissolved at temperatures below the boiling points of their solvents. Blend solutions of PS with PPPE and PS with HDPE were prepared by mixing the individual polymer stock solutions at different compositions at a constant concentration of $10 \mathrm{mg} / \mathrm{mL}$. Blend solutions were stirred mechanically for $2-3 \mathrm{~h}$ at $60^{\circ} \mathrm{C}$ to reach equilibrium when $\mathrm{THF} / \mathrm{xylene}$ mixture was used and at $115^{\circ} \mathrm{C}$ when only xylene was used. Pure ethanol (v/v 99.8\%) was added drop-wise into the blend solution when non-solvent 
addition was required to obtain more rough surfaces. Dip coating of the round glass coverslips by blend polymers was performed with a mechanical dipper which moves vertically at a constant removal speed of $320-784 \mathrm{~mm} / \mathrm{min}$. Coated polymer films were kept in a desiccator for 3-4 h and completely dried in a vacuum oven at $40^{\circ} \mathrm{C}$ overnight. The thicknesses of the coatings varied between 0.5 and $2.0 \mu \mathrm{m}$.

\section{Characterization of polymers}

Static water contact angles under air were measured using a KSV-CAM 200 contact angle meter with a PC controlled motorized syringe within $\pm 1^{\circ}$ precision. The equilibrium contact angle values $\left(\theta_{\mathrm{e}}\right)$ were determined after the needle was removed from a $5 \mu \mathrm{L}$ droplet formed on the solid surface. Only the initial values, which were recorded within $2 \mathrm{~s}$ following the removal of the needle from the droplet, were reported as $\theta_{\mathrm{e}}$. In addition, we measured both advancing $\left(\theta_{\mathrm{a}}\right)$ and receding $\left(\theta_{\mathrm{r}}\right)$ water contact angles on the sample surfaces by increasing the volume of the droplets from 3 to $8 \mu \mathrm{L}$ and decreasing from 8 to $4 \mu \mathrm{L}$, respectively, through the needle using the automatic dispenser while the needle was kept within the liquid droplet. The receding contact angles were also measured by drop evaporation method for better precision. $^{24,25}$ The surface topography of rough polymer blends was examined by optical microscopy, 3D profilometry (Nikon, Eclipse-LV100D Microscope with a Clemex Camera using Clemex Professional Edition, Image Analyzing System with 3D Modeling Module and Motorized Stage), and environmental scanning electron microscopy (ESEM, Quanta 200 FEG).

\section{Cell culture and maintenance}

All in vitro cell culture experiments on polymer-coated surfaces were performed with Saos-2 human osteosarcoma cells (ATCC $^{\circledR}$ HTB-85 $5^{\mathrm{TM}}$ ) and human gingival fibroblasts (HGF). HGF cells were kindly provided as a gift from Prof. Dr. A. U. Ural (GATA, Ankara, Turkey). Both cells were maintained in Dulbecco's Modified Eagle Medium supplemented with $10 \%$ FBS and $1 \%$ penicillin/streptomycin at $37^{\circ} \mathrm{C}$ in a humidified $5 \% \mathrm{CO}_{2}$ chamber. Media were changed twice weekly and cultures of $90 \%$ confluent cells were detached with $0.25 \%$ trypsin-EDTA and resuspended in fresh media.

\section{Adhesion, spreading, and cellular morphology analysis} of Saos-2 and HGF cells on polymer-coated surfaces

All coated surfaces were sterilized under UV light prior to experiments. Before adhesion experiments were performed, cells were incubated in serum-free media containing $4 \mathrm{mg} /$ $\mathrm{mL}$ BSA and $50 \mu \mathrm{g} / \mathrm{mL}$ cyclohexamide for $1 \mathrm{~h}$ under standard cell culture conditions $\left(37^{\circ} \mathrm{C}, 5 \% \mathrm{CO}_{2}\right.$, and $95 \%$ humidity). Bare glass surfaces were used as reference material. Polymer-coated and uncoated glass coverslips were placed into 24-well plates and cells were seeded on surfaces at densities of 15,000 cells $/ \mathrm{cm}^{2}$ in serum-free media. After $1 \mathrm{~h}$ of incubation, surfaces were washed with HBSS (Hank's Balanced Salt Solution) and remaining attached cells were stained with $1 \mu \mathrm{M}$ Calcein AM for $30 \mathrm{~min}$. At least five random photos were taken from each well and cells were counted with Image J. To visualize actin cytoskeleton of the cells on substrates, cells were fixed with $3.7 \%$ formaldehyde after washing with HBSS, permeabilized with $0.25 \%$ Triton$\mathrm{X}$, stained with TRITC-conjugated phalloidin, and photographed using a confocal microscope (Zeiss LSM 510). Morphology of Saos- 2 and HGF cells was characterized by SEM. Cells were seeded on polymer-coated glass surfaces at densities of 15,000 cells $/ \mathrm{cm}^{2}$ in complete growth medium. After $48 \mathrm{~h}$, cells were washed with HBSS and fixed in $2 \%$ gluteraldehyde solution followed by dehydration in increasing alcohol concentrations, dried with critical point-dryer (Tourismis Autosamdri $\left.{ }^{\circledR}-815 \mathrm{~B}\right)$, and imaged with a scanning electron microscope (FEI Quanta 200 FEG).

\section{Viability of Saos-2 cells}

Polymer-coated or bare glass surfaces were placed in 24well plates. Surfaces were UV sterilized prior to experiments. Cells were seeded on surfaces at densities of 15,000 cells $/ \mathrm{cm}^{2}$ in complete growth medium. Viability and proliferation experiments of cells on surfaces after 24 and $48 \mathrm{~h}$ of incubation were performed using in vitro toxicity assay kit-MTT (Sigma) according to manufacturer's protocol. Absorbance of dye was measured at a wavelength of 570 $\mathrm{nm}$ with background subtraction at $690 \mathrm{~nm}$ by SpectraMax M5 Multi-Mode Microplate Reader.

\section{Statistical analysis}

Cell adhesion, viability, and spreading on surfaces were analyzed in triplicate $(n=3)$ and all the statistical analyses were obtained in three independent experiments. Error bars represent standard error of the mean. Statistical significance was determined using one-way or two-way ANOVA depending on the experiment with a confidence interval of $p<0.05$.

\section{RESULTS AND DISCUSSON}

\section{Fabrication and characterization of polymer thin films}

Surface chemical composition, roughness, and wettability have substantial effects on the attachment, proliferation, and morphological characteristics of cells. Seven different polymer surfaces with various topographies and wettabilities were synthesized: polyvinyl alcohol (PVOH), polystyrene (PS), high density polyethylene (HDPE) polymers; polypropylene polyethylene (PPPE) co-polymer; sulfonated polystyrene (PS-S); PS/HDPE blend and PPPE/PS blend with EtOH as non-solvent. Equilibrium $\left(\theta_{\mathrm{e}}\right)$, advancing $\left(\theta_{\text {adv }}\right)$, and receding $\left(\theta_{\text {rec }}\right)$ water contact angles were measured by a contact angle meter, and surface roughness by profilometry (Supporting Information Table S1). Equilibrium water contact angles measured for pure PVOH, PS, HDPE, and PPPE were found to be similar to those reported in the literature for these polymers. ${ }^{26-29}$ Contact angle hysteresis $(\mathrm{CAH})$, which is an indicator of surface heterogeneity and is observed when the system does not meet the ideal conditions, was calculated by subtracting $\theta_{\text {rec }}$ from $\theta_{\text {adv }}$ CAH values were found to range between 10 and $32^{\circ}$. $\mathrm{PVOH}$ surface was the most hydrophilic one due to the presence of hydroxyl groups. PS-S film was more hydrophilic than PS because of surface sulfonation; moreover, CAH value of PS-S 
TABLE I. Chemical Composition, Water Contact Angle $\left(\theta_{\mathrm{e}}\right)$ with Advancing $\left(\theta_{\text {adv }}\right)$ and Receding $\left(\theta_{\text {rec }}\right)$ Values, CAH, and Surface Roughness ( $R_{\text {RMs }}$ ) Measurements of PPPE/PS Phase Separated Polymer-Coated Surfaces

\begin{tabular}{|c|c|c|c|c|c|c|}
\hline Polymer Code & $\mathrm{EtOH} \%(\mathrm{v} / \mathrm{v})$ & $\theta_{\mathrm{e}}$ & $\theta_{\mathrm{adv}}$ & $\theta_{\text {rec }}$ & $\mathrm{CAH}$ & $\mathrm{R}_{\mathrm{RMS}}$ \\
\hline PPPE(EtOH) & 10 & 106 & 112 & 89 & 23 & N.A. \\
\hline $\mathrm{PPPE}_{80} / \mathrm{PS}_{20}(\mathrm{EtOH})$ & 10 & 105 & 111 & 81 & 30 & 0.15 \\
\hline $\mathrm{PPPE}_{70} / \mathrm{PS}_{30}(\mathrm{EtOH})$ & 10 & 106 & 110 & 90 & 20 & 0.16 \\
\hline $\mathrm{PPPE}_{50} / \mathrm{PS}_{5} \mathrm{O}(\mathrm{EtOH})$ & 10 & 106 & 109 & 88 & 21 & 0.18 \\
\hline $\mathrm{PPPE}_{30} / \mathrm{PS}_{70}(\mathrm{EtOH})$ & 10 & 107 & 111 & 87 & 24 & 0.23 \\
\hline PS (EtOH) & 10 & 100 & 101 & 87 & 14 & N.A. \\
\hline
\end{tabular}

film was two times higher than that of PS surface due to surface heterogeneity.

Surface morphologies of the coatings were determined by optical microscopy and SEM imaging. Pure PVOH, pure PS, and PS-S surfaces showed rather smooth topographies as they looked flat under SEM for $40,000 \times$ magnification. Pure PPPE film showed low amounts of roughness. Large spherulites ranging between 10 and $20 \mu \mathrm{m}$ were observed on HDPE surface. SEM image in the inset (Supporting Information Fig. S1) shows nanofibrillar structures which were less than $1 \mu \mathrm{m}$. Thicknesses of PS and PS-S films were around 1.5-2 $\mu \mathrm{m}$, and PVOH was less than $1 \mu \mathrm{m}$ which were calculated by measuring the increase in sample weight after preparation. Phaseseparated polymer thin films exhibited micro-structures with various diameters. $\mathrm{PS}_{50} / \mathrm{HDPE}_{50}$ polymer blend film contained PS micropatterns ranging between 5 and $15 \mu \mathrm{m}$ in diameter (Supporting Information Fig. S1) similar to previous studies. ${ }^{30,31}$ As HDPE has lower molecular weight and lower surface energy than PS, HDPE tends to cover the surface of PS $_{50} /$ HDPE $_{50}$ film to minimize interface tension between polymer and air, resulting in PS microisland formation. Water contact angle of PS/HDPE surface $\left(101^{\circ}\right)$ was in between water contact angles of PS $\left(93^{\circ}\right)$ and $\operatorname{HDPE}\left(105^{\circ}\right)$. SEM and optical microscopy images of PPPE/PS (EtOH) polymer blend thin film are displayed in Supporting Information Figure S3 $\left(\mathrm{PPPE}_{60} / \mathrm{PS}_{40} 10 \% \mathrm{EtOH}\right)$. Micro-patterns were stable under standard cell culture conditions for all surfaces.

\section{Cellular behaviors on polymer thin films}

For successful osseointegration of the implants, osteoblast adhesion is crucial and the formation of fibrous tissue should be prevented. To find the optimal surface for osseointegration, polymer-coated coverglass surfaces with various chemical heterogeneity, wettability, and surface roughness properties were tested for their effects on shortterm adhesion profiles of Saos-2 human osteoblast-like cell line and human gingival fibroblasts (HGFs).

Short-term adhesion is governed by weak interactions between the surface and cells. This non-receptor-mediated cell adhesion occurs via interactions such as hydrogen bonding, electrostatic, polar, or ionic interactions between molecules on cell membrane and various chemical groups on materials' surfaces. Cells were incubated in serum-free media containing $50 \mu \mathrm{g} / \mathrm{mL}$ cyclohexamide for $1 \mathrm{~h}$ in standard cell culture conditions to prevent protein interference with adhesion events and protein synthesis, respectively. As a result, extracellular matrix deposition on the surfaces was eliminated. Adhesion of Saos- 2 cells had a tendency to increase with hydrophobicity [Supporting Information Fig. S2(a)]. Saos-2 cells adhered on hydrophobic surfaces independent from their roughness amplitude and chemistry suggesting that main factor on initial osteoblast attachment is surface wettability.

Cell adhesion on surfaces is also dependent on cell type. ${ }^{32}$ In contrast to enhanced Saos-2 adhesion on hydrophobic surfaces, HGF adhesion does not show a distinct preference to wettability of the surfaces [Supporting Information Fig. S2(b)]. It was also previously shown that fibroblast cells are not very sensitive to the changes in surface wettability and that they can adhere on both hydrophilic and hydrophobic surfaces. ${ }^{7}$ The lowest HGF adhesion was observed on PPPE/PS (EtOH) surface. Surfaces coated with PPPE/PS (EtOH) supported selective osteoblast-like cell adhesion while inhibiting fibroblast adhesion.

\section{Fabrication and characterization of PPPE/PS blend thin films}

To obtain substrates with distinct morphologies; six different polymer solutions containing different PPPE/PS ratios with same EtOH amount (10\%, v/v) were synthesized (Table I). EtOH was added as a non-solvent to increase surface heterogeneity. Polymer droplets formed on the surfaces after dip coating led to formation of various morphologies that exhibited holes and rips with various diameters and different separation distances. Their contact angle and rms roughness values are presented in Table I. Surface roughness and chemical composition are two important factors that determine the wetting properties of a surface. ${ }^{33}$ All PPPE/PS (EtOH) polymer thin films had closely similar equilibrium water contact angles. Furthermore, their $\theta_{\mathrm{e}}$ values were comparable to those of PPPE (EtOH) surface regardless of their polymer composition ratio. This indicates that the surfaces of coverslips were enriched by PPPE copolymer during phase separation. This might be due to the lower surface free energy of PPPE $\left(30.8 \mathrm{~mJ} / \mathrm{m}^{2}\right)$ compared to PS $\left(40.6 \mathrm{~mJ} / \mathrm{m}^{2}\right)$; hence, PPPE enrichment decreased the free energy of surfaces. Surface free energies were calculated using van Oss-ChaudhuryGood method. ${ }^{34}$ Surface characterizations of the polymer compositions were performed with optical microscopy and SEM (Fig. 1). Because of the immiscibility of two polymers, islands-which were single protrusions of micropatternswere formed to minimize the contact surface. Diameters of micro-structures ranged between 2.5 and $10 \mu \mathrm{m}$ depending on the PPPE/PS composition. PS (EtOH) film was smooth whereas PPPE (EtOH) film had little roughness. Combination of these results indicates that PPPE/PS (EtOH) surfaces had a PPPE matrix with PS micro-structures. The overall characteristics of PPPE/PS (EtOH) surfaces showed that micro-islands formed by PS polymer determined surface roughness; however, coverslips were covered with PPPE upper layer which determined their water contact angle values.

In addition, $\mathrm{PPPE}_{60} / \mathrm{PS}_{40}$ polymer solutions containing various EtOH amounts (4\%, 10\%, 14\%, 18\% v/v) were 

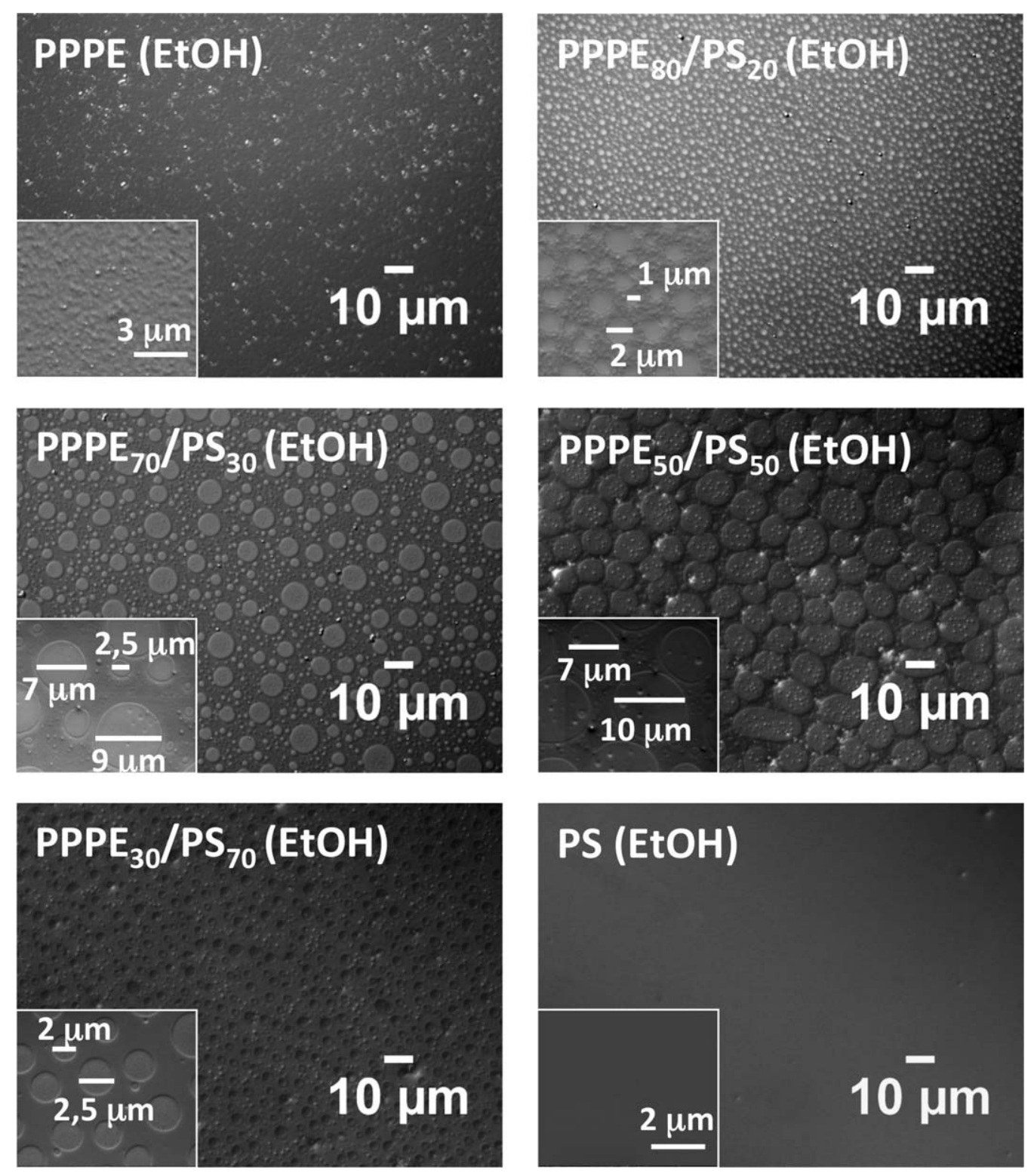

FIGURE 1. Optical microscopy and SEM images of PS (EtOH) homopolymer, PPPE (EtOH) copolymer, and various combinations of PPPE/PS (EtOH) polymer blend surface coatings. All surfaces contained $10 \%(\mathrm{v} / \mathrm{v}) \mathrm{EtOH}$ as non-solvent.

synthesized to analyze the effect of EtOH as non-solvent (Supporting Information Table S2). For $\mathrm{PPPE}_{60} / \mathrm{PS}_{40}$ polymer thin films, increasing the amount of EtOH increased $\mathrm{CAH}$ value, indicating an increase in surface heterogeneity. Optical microscopy and SEM images of these surfaces are presented in Supporting Information Figure S3. The diameters of micro-structures ranged between 5 to $18 \mu \mathrm{m}$.

\section{Cellular behaviors on PPPE/PS thin films}

Viability of Saos-2 cells on PPPE/PS (EtOH) thin films was determined 24 and $48 \mathrm{~h}$ after cell seeding in complete medium (Fig. 2). Cell numbers were normalized to bare coverglass surface at $24 \mathrm{~h}$. After $24 \mathrm{~h}$, there was no significant difference between the numbers of cells on any polymercoated surfaces and bare glass. After 48 h, Saos- 2 cells showed significant increase in cell number on all surfaces excluding PS (EtOH). Relative cell number did not change on PS (EtOH) surface after $48 \mathrm{~h}$. These results indicate the compatibility of the surfaces.

Adhesion of Saos- 2 and HGF cells on pure polymers and phase-separated polymer thin films was assessed to analyze the effect of surface topography and chemical composition on cellular attachment. Initial adhesion resulted in serumfree media is shown in Figure 3. On heterogeneous PPPE/ PS (EtOH) thin films, Saos-2 adhesion profiles varied depending on PPPE/PS ratio. Saos-2 adhesion was enhanced most significantly on $\mathrm{PPPE}_{50} / \mathrm{PS}_{50}$ (EtOH) surface. Relative Saos-2 adhesion was observed to decrease with decreasing fractions of PS on the surface. However, cell adhesion also decreased $1.46 \pm 0.19$ and $3.87 \pm 0.16$ times when PS fraction was $70 \%$ and $100 \%$, respectively (Fig. 3). Whereas, the only significant increase in HGF adhesion was observed on 


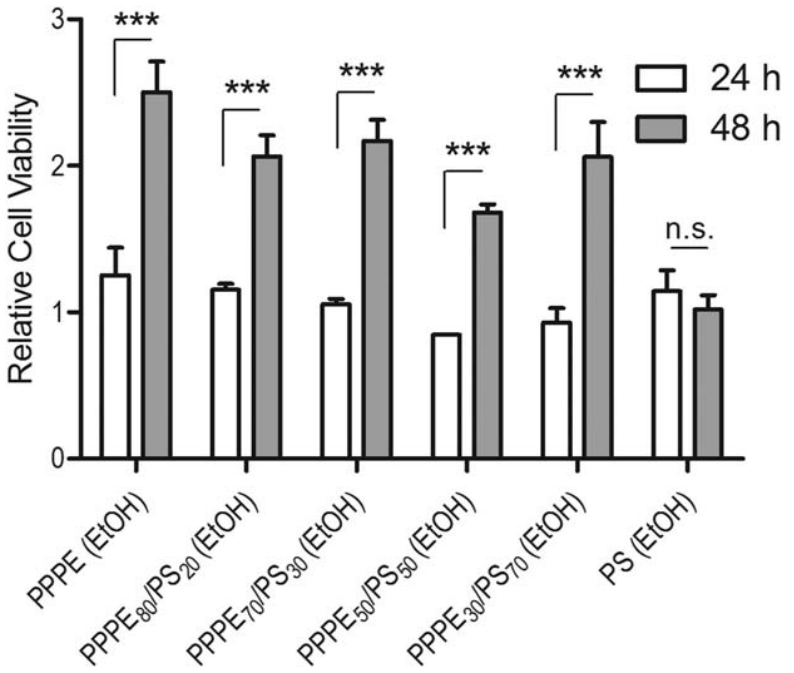

FIGURE 2. Viability of Saos-2 cells on 24th and 48th h of post-seeding shows compatibility of polymer-coated surfaces. Cell numbers were normalized to uncoated coverglass surface at $24 \mathrm{~h}(n=3)$. Error bars indicate standard error of mean $(n=3)$. Statistical significance was determined using two-way ANOVA with Bonferroni post-test. ${ }^{* * *} p<0.001$, n.s $\left.p>0.05\right)$.

$\mathrm{PPPE}_{50} / \mathrm{PS}_{50}$ (EtOH) surface (Fig. 3). The results indicate that initial cell attachment of both cell types was enhanced on $\mathrm{PPPE}_{50} / \mathrm{PS}_{50}$ (EtOH) polymer blend surfaces when compared to other groups. All surfaces showed positive selectivity towards Saos-2 attachment as the relative Saos-2 adhesion showed between $3.31 \pm 0.04$ and $9.43 \pm 0.11$-fold increase when compared to relative HGF attachment.

Initial adhesion of Saos-2 and HGF cells was also evaluated on $\mathrm{PPPE}_{60} / \mathrm{PS}_{40}$ polymer surfaces with various amounts of EtOH (Supporting Information Fig. S4). Although all surfaces showed positive selectivity towards Saos-2 cells, increase in EtOH amount did not cause significant changes in neither Saos-2 nor HGF adhesion for the same chemical composition.

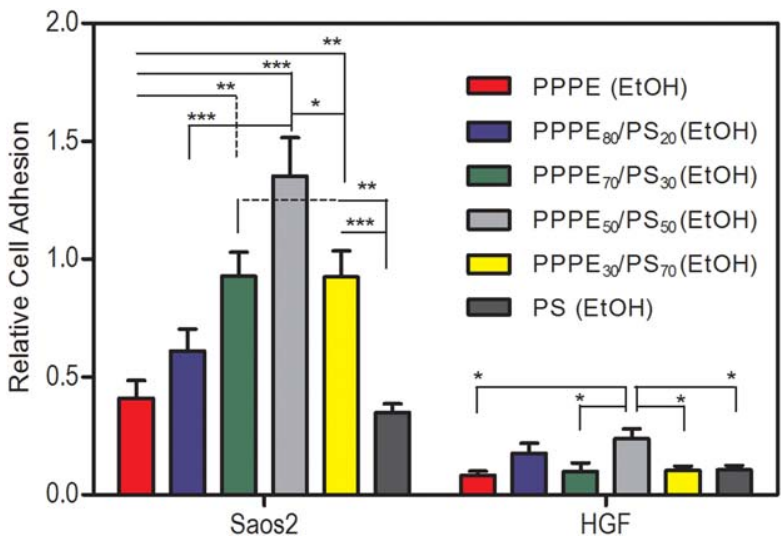

FIGURE 3. In vitro adhesion analysis of Saos2 and HGF cells on PPPE (EtOH), PS (EtOH), and PPPE/PS (EtOH) surfaces. Adhesion was quantified by counting Calcein-AM stained cells $1 \mathrm{~h}$ post-seeding. Results were normalized to bare coverglass surfaces. Error bars indicate standard error of the mean $(n=3)$. Statistical significance was determined using one-way ANOVA with Tukey's multiple comparison test. $\left.{ }^{*} p<0.05,{ }^{* *} p<0.01,{ }^{* *} p<0.001\right)$. [Color figure can be viewed in the online issue, which is available at wileyonlinelibrary.com.]
Initial adhesion of cells on the surfaces is followed by deposition of ECM biomacromolecules on material surfaces by cells, which in turn are recognized by membrane proteins. Recognition of specific bioactive ligands presented by the extracellular matrix layer on material's surface through receptor recruitment stimulates intracellular processes and interactions of these receptors with cytoskeletal elements which in turn determine cell spreading behaviors of attached cells. ${ }^{35}$ To analyze spreading behaviors of cells, their cytoskeletal organization on polymer thin films was visualized by F-actin staining. On the 48th $\mathrm{h}$ of post seeding, Saos- 2 cells showed highly oriented actin filaments with stress fibers running in all directions on all surfaces (Fig. 4). To further investigate cell morphologies on the materials, SEM imaging was conducted (Fig. 5). Saos-2 cells displayed their typical morphology on all surfaces. Surface patterns are not visible due to protein adsorption and post-fixation steps.

HGF cells presented normal spindle-shaped morphology on all surfaces after $48 \mathrm{~h}$ (Supporting Information Fig. S5). Although initial attachment of HGF cells in serum-free media was not supported by PPPE/PS + EtOH surfaces, they presented a normal morphology after longer periods of incubation. This suggests that the orientation of adsorbed protein layer and the presented ligands on the surfaces might support HGF adhesion and determine the morphology of HGF cells in long-term.

\section{CONCLUSIONS}

In this work, we showed how the changes in physicochemistry of materials led to significant differences in short- and long-term adhesion of different cell types. Various wettabilities, micro-scales, and chemical compositions were acquired with different polymer thin films prepared using phase separation method with dip-coating. Osteoblast-like cells (Saos2) and fibroblasts (HGF) were used as model systems for assessing suitability of surfaces as implant coatings. Although they are more mature and do not reflect the whole phenotypic properties of primary cells, Saos- 2 cells show many advantages like easy handling and maintenance; moreover, their cytokine and growth factor expression levels are similar to human primary osteoblasts which make them good candidates for tissue engineering studies. ${ }^{36,37}$ We found that initial Saos-2 adhesion was enhanced with the increase in hydrophobicity and chemical heterogeneity. The same conditions did not support HGF initial attachment.

The key fundamental properties of scaffolds used as implants are good adhesion capabilities with the desired cells, good mechanical properties, and stability. ${ }^{38}$ The main challenge in surface modification for implants comes when the surface is exposed to human body environment. However, many successful applications have previously been shown with case studies dealing with orthopedic and dental coatings. ${ }^{39,40}$

This study showed that using cheap and easy to prepare heterogeneous polymers, we can create cell selective surface coatings that are able to induce appropriate cell-surface interactions. These surfaces can be used as implant coating materials that can increase success of implant osseointegration. 

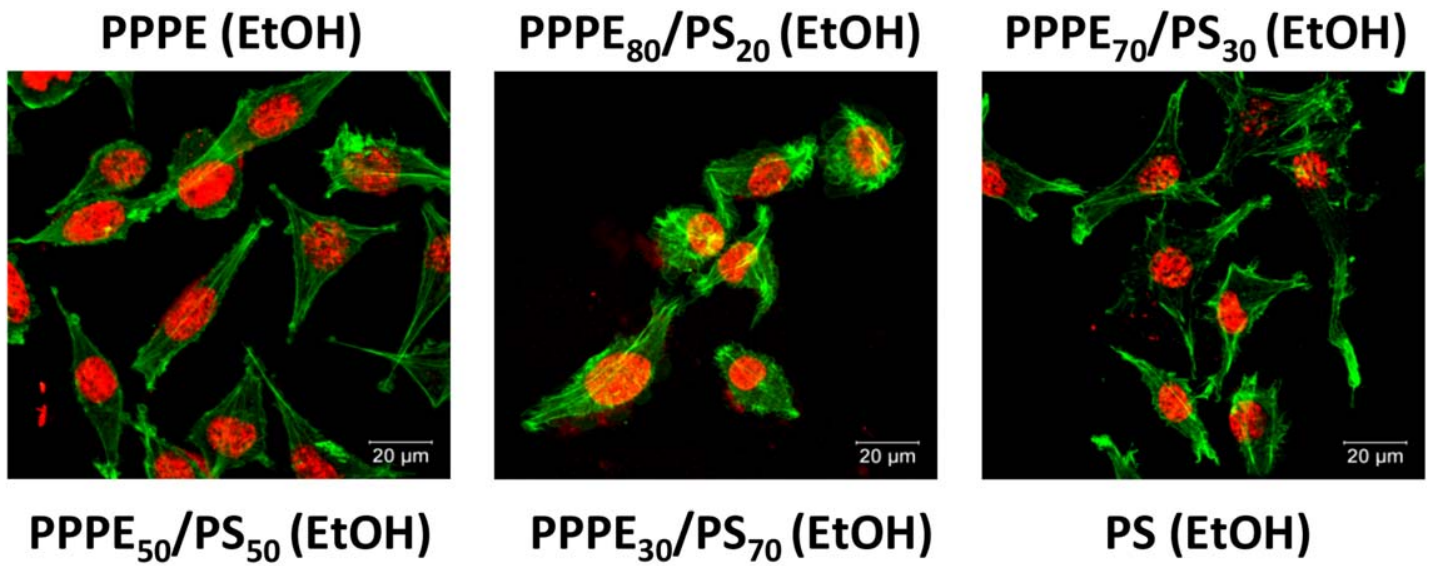

PS (EtOH)
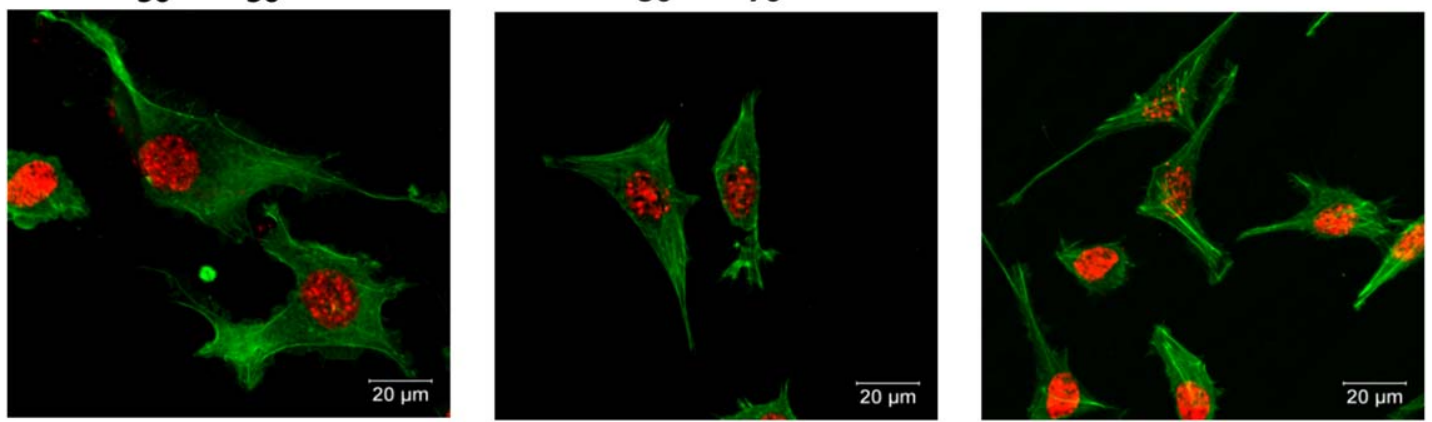

FIGURE 4. Confocal images showing cytoskeletal organization of Saos-2 cells on polymer thin films after $48 \mathrm{~h}$ of incubation. Actin cytoskeleton was visualized by TRITC-Phalloidin (green) and cell nucleus by TO-PRO staining (red). [Color figure can be viewed in the online issue, which is available at wileyonlinelibrary.com.]
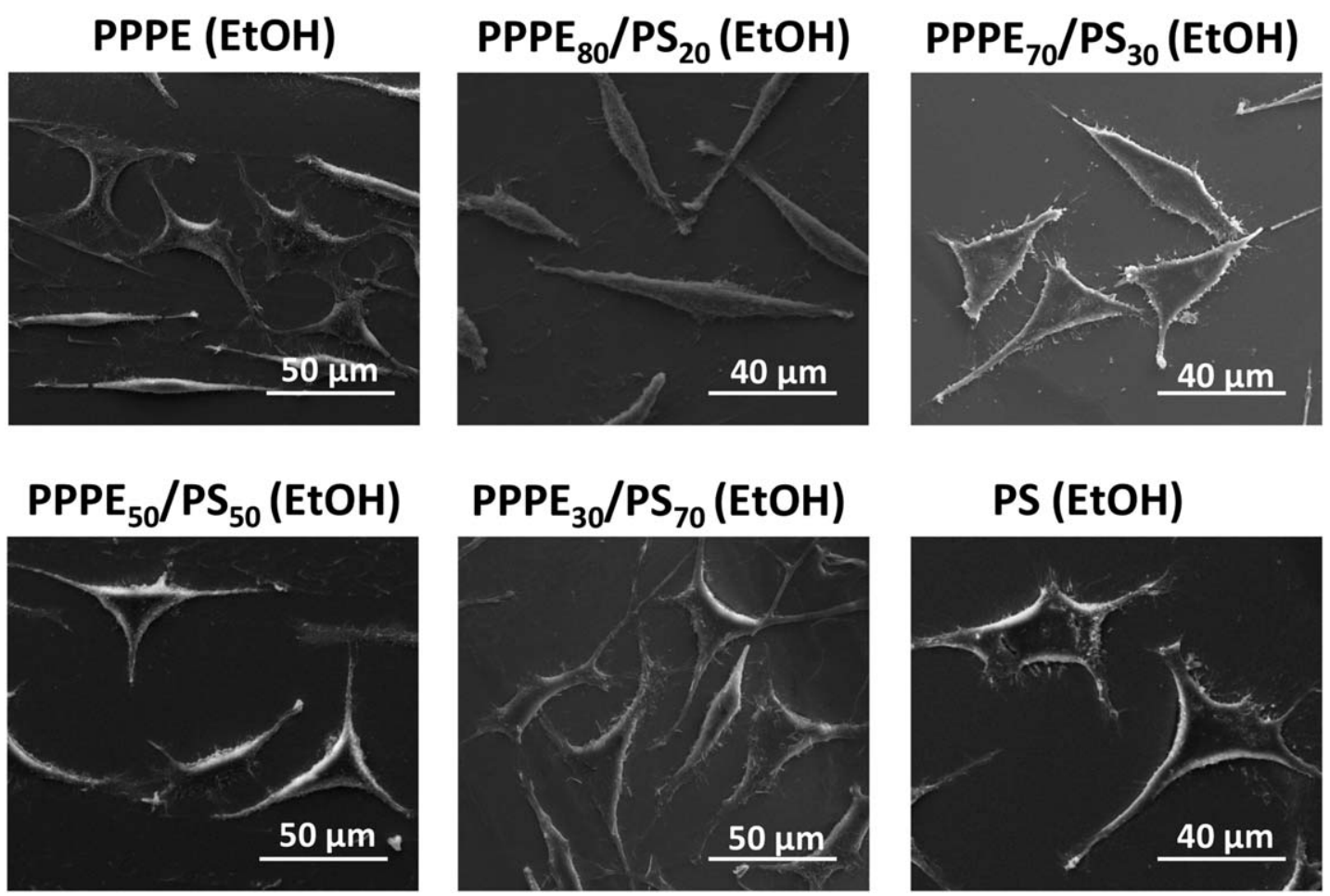

FIGURE 5. SEM images exhibited morphologies of Saos-2 cells on polymer thin films with various PPPE (EtOH) and PS (EtOH) compositions 48 h post-seeding. 
Periodontal and orthopedic applications require the use of either titanium or stainless steel materials. Therefore, to fully appreciate the usage of these polymer coatings in medical applications, this method of preparing polymer thin films on glass should be applied to titanium and stainless steel surfaces and optimized accordingly. Additionally, evaluation of the mechanical behaviors of the surfaces is needed for therapeutic applications to optimize the lifetime of the implants.

\section{ACKNOWLEDGMENT}

A.B.T. acknowledges support from the Turkish Academy of Sciences Distinguished Young Scientist Award (TUBA GEBIP).

\section{REFERENCES}

1. Le Guehennec $L$, Soueidan A, Layrolle $P$, Amouriq $Y$. Surface treatments of titanium dental implants for rapid osseointegration. Dent Mater 2007;23:844-854.

2. Kilpadi KL, Chang P-L, Bellis SL. Hydroxylapatite binds more serum proteins, purified integrins, and osteoblast precursor cells than titanium or steel. J Biomed Mater Res 2001;57:258-267.

3. Dekeyser CM, Zuyderhoff E, Giuliano RE, Federoff HJ, DupontGillain CC, Rouxhet PG. A rough morphology of the adsorbed fibronectin layer favors adhesion of neuronal cells. J Biomed Mater Res Part A 2008;87A:116-128.

4. Rosales-Leal JI, Rodriguez -Valverde MA, Mazzaglia G, Ramon Torregrosa PJ, Diaz-Rodriguez L, Garcia-Martinez O, VallecilloCapillaa M, Ruizc C, Cabrerizo-Vílchez MA. Effect of roughness, wettability and morphology of engineered titanium surfaces on osteoblast-like cell adhesion. Colloids and Surfaces A: Physicochemical and Engineering Aspects 2010;365:222-229.

5. Schakenraad JM, Busscher HJ, Wildevuur $\mathrm{CRH}$, Arends J. The influence of substratum surface free energy on growth and spreading of human fibroblasts in the presence and absence of serum proteins. J Biomed Mater Res 1986;20:773-784.

6. Lee $\mathrm{JH}$, Jeong $\mathrm{BJ}$, Lee HB. Plasma protein adsorption and platelet adhesion onto comb-like PEO gradient surfaces. J Biomed Mater Res 1997;34:105-114.

7. Ruardy TG, Moorlag HE, Schakenraad JM, Van Der Mei HC, Busscher HJ. Growth of fibroblasts and endothelial cells on wettability gradient surfaces. J Colloid Interface Sci 1997;188:209-217.

8. Elliott JT, Woodward JT, Umarji A, Mei Y, Tona A. The effect of surface chemistry on the formation of thin films of native fibrillar collagen. Biomaterials 2007;28:576-585.

9. van der Valk $P$, van Pelt AWJ, Busscher $H J$, de Jong $H P$, Wildevuur $\mathrm{CRH}$, Arends J. Interaction of fibroblasts and polymer surfaces: Relationship between surface free energy and fibroblast spreading. J Biomed Mater Res 1983;17:807-817.

10. Ruardy TG, Schakenraad JM, van der Mei HC, Busscher HJ. Adhesion and spreading of human skin fibroblasts on physicochemically characterized gradient surfaces. J Biomed Mater Res 1995 29:1415-1423.

11. Ceylan H, Kocabey S, Tekinay AB, Guler MO. Surface-adhesive and osteogenic self-assembled peptide nanofibers for bioinspired functionalization of titanium surfaces. Soft Matter 2012;8:3929-3937.

12. Flemming RG, Murphy CJ, Abrams GA, Goodman SL, Nealey PF. Effects of synthetic micro- and nano-structured surfaces on cell behavior. Biomaterials 1999;20:573-588.

13. Orsini E, Salgarello S, Martini D, Bacchelli B, Quaranta M, Pisoni L, Bellei E, Joechler M, Ottani V. Early healing events around titanium implant devices with different surface microtopography: A pilot study in an in vivo rabbit model. ScientificWorldJournal 2012;2012:9.

14. Olivares-Navarrete $R$, Raz $P$, Zhao G, Chen J, Wieland M, Cochran DL, Chaudhri RA, Ornoy A, Boyan BD, Schwartz Z. Integrin $\alpha 2 \beta 1$ plays a critical role in osteoblast response to micron-scale surface structure and surface energy of titanium substrates. Proc Nat Acad Sci USA 2008;105:15767-15772.

15. Keselowsky BG, Collard DM, Garcia AJ. Surface chemistry modulates fibronectin conformation and directs integrin binding and specificity to control cell adhesion. J Biomed Mater Res Part A 2003;66A:247-259.
16. Berciaud S, Cognet L, Blab GA, Lounis B. Photothermal heterodyne imaging of individual nonfluorescent nanoclusters and nanocrystals. Phys Rev Lett 2004;93:257402.

17. Keren S, Zavaleta C, Cheng Z, de la Zerda A, Gheysens O, Gambhir SS. Noninvasive molecular imaging of small living subjects using Raman spectroscopy. Proc Natl Acad Sci USA 2008; 105:5844-5849.

18. Zavaleta CL, Smith BR, Walton I, Doering W, Davis G, Shojaei B, Natanb MJ, Gambhir SS. Multiplexed imaging of surface enhanced Raman scattering nanotags in living mice using noninvasive Raman spectroscopy. Proc Natl Acad Sci USA 2009;106: 13511-13516.

19. Ishizaki T, Saito N, Takai O. Correlation of cell adhesive behaviors on superhydrophobic, superhydrophilic, and micropatterned superhydrophobic/superhydrophilic surfaces to their surface chemistry. Langmuir 2010;26:8147-81454.

20. Tsai D-H, Elzey S, DelRio FW, Keene AM, Tyner KM, Clogston JD, et al. Tumor necrosis factor interaction with gold nanoparticles. Nanoscale 2012;4:3208-3217.

21. Vendra VK, Wu L, Krishnan S. Polymer thin films for biomedical applications. Nanotechnologies for the Life Sciences. Weinheim: Wiley-VCH Verlag GmbH \& Co. KGaA; 2011.

22. Dhandayuthapani B, Yoshida Y, Maekawa T, Kumar DS. Polymeric scaffolds in tissue engineering application: A review. Int $\mathrm{J}$ Polym Sci 2011;2011.

23. Erbil HY, Demirel AL, Avcı Y, Mert O. Transformation of a simple plastic into a superhydrophobic surface. Science 2003;299:1377-1380.

24. Erbil HY, McHale G, Rowan SM, Newton MI. Determination of the receding contact angle of sessile drops on polymer surfaces by evaporation. Langmuir 1999;15:7378-7385.

25. Erbil HY. Surface Chemistry of Solid and Liquid Interfaces. Oxford: Blackwell Publishing; 2006.

26. Zuyderhoff EM, Dupont-Gillain CC. Nano-organized collagen layers obtained by adsorption on phase-separated polymer thin films. Langmuir 2011;28:2007-2014.

27. Ucar I, Cansoy CE, Erbil HY, Pettitt M, Callow M, Callow J. Effect of contact angle hysteresis on the removal of the sporelings of the green alga Ulva from the fouling-release coatings synthesized from polyolefin polymers. Biointerphases 2010;5:75-84.

28. Nishino T, Meguro M, Nakamae K. Poly(vinyl alcohol) with low surface free energy by fluorination. Int J Adhes Adhes 1999;19:399-403.

29. Mittal KL. Contact Angle, Wettability and Adhesion. Boston: Brill Academic Pub; 2009.

30. Lee JK, Han CD. Evolution of polymer blend morphology during compounding in an internal mixer. Polymer 1999;40:6277-6296.

31. Virgilio N, Marc-Aurele C, Favis BD. Novel self-assembling closepacked droplet array at the interface in ternary polymer blends. Macromolecules 2009;42:3405-3416.

32. Oliveira SM, Song W, Alves NM, Mano JF. Chemical modification of bioinspired superhydrophobic polystyrene surfaces to control cell attachment/proliferation. Soft Matter 2011;7:8932-8941.

33. Egatz-Gomez A, Majithia R, Levert C, Meissner KE. Super-wetting, wafer-sized silicon nanowire surfaces with hierarchical roughness and low defects. RSC Advances 2012;2:11472-11480.

34. Van Oss CJ, Chaudhury MK, Good RJ. Interfacial Lifshitz-van der Waals and polar interactions in macroscopic systems. Chem Rev 1988;88:927-941.

35. Anselme K, Bigerelle M. Modelling approach in cell/material interactions studies. Biomaterials 2006;27:1187-1199.

36. Bilbe G, Roberts E, Birch M, Evans DB. PCR phenotyping of cytokines, growth factors and their receptors and bone matrix proteins in human osteoblast-like cell lines. Bone 1996;19:437-445.

37. Czekanska EM, Stoddart MJ, Richards RG, Hayes JS. In search of an osteoblast cell model for in vitro research. Eur Cell Mater 2012;24:1-17.

38. Sabir M, Xu X, Li L. A review on biodegradable polymeric materials for bone tissue engineering applications. J Mater Sci 2009;44: 5713-5724.

39. Frank RM, Fabi D, Levine BR. Modern porous coatings in orthopaedic applications. In: Nazarpour S, editor. Thin Films and Coatings in Biology. Netherlands: Springer; 2014. p 69-103.

40. Chen X, Li Y, Aparicio C. Biofunctional coatings for dental implants. In: Nazarpour S, editor. Thin Films and Coatings in Biology. Netherlands: Springer; 2014. p 105-143. 